\title{
Optimization of Fermentation Process Parameters for Bioethanol Production from Sri Lankan Overripe Fruits
}

\author{
I.W. Kularathne, C.A. Gunathilaka, A.C. Ratnaweera, C.S. Kalpage, \\ S. Rajapakse and P. Gamage
}

\begin{abstract}
Bioethanol produced by biomaterials is used in many countries around the world as an alternative option for gasoline, mainly due to its better emission characteristics. Presently, Sri Lanka depends on imported fossil fuel to fulfil the majority of its transportation fuel requirement and also committed to reduce green house gas emission. Therefore, searching for alternative freely available and low-cost bio resources to produce bioethanol is a timely requirement. This research aims to study the possibility of producing bioethanol from Sri Lankan rotten fruits (without skin) using batch fermentation followed by optimization of the fermentation process parameters. Optimization is carried out by using Response Surface Methodology (RSM) and Genetic Algorithm (GA), and Particle Swarm Optimization (PSO). Bioethanol production is carried out using three different overripe fruits: Banana (Musa ssp.) embul kesel variety, Papaya (Carica-papaya) and Jackfruit (Artocarpus heterophyllus) with two different microorganisms (inoculum) at three different fermentation conditions. The maximum ethanol yield (\%) obtained with RMS, GA and PSO were 13.39, 13.39, and 13.36 vol.\%, respectively, by using Banana (embul kesel variety) fermentation with Pseudomonas mendocina (PM) as inoculum, $1: 1$ substrate concentration, $5.1 \mathrm{pH}$ and $35^{\circ} \mathrm{C}$ temperature conditions.
\end{abstract}

Keywords: Bioethanol, Overripe Fruits, Microorganisms, Fermentation, Optimization

\section{Introduction}

Energy crisis and environmental issues catalysed the researchers to discover alternative and renewable energy sources as a replacement for fossil energy sources. As a result, biofuel produced by biomass has been identified as the best alternative energy source due to several merits [1][2]. Presently, Sri Lanka depends on imported fossil fuel for the transportation fuel requirement, even though sugar and starchbased bioethanol feedstocks are well grown in Sri Lanka. Considering the limited cultivable lands and food security issues in Sri Lanka, bioethanol production using such feedstocks is discouraged [3]. Although lignocellulose materials such as agricultural residues, wood, paper and municipal solid waste are cheaper than sugar-containing biomaterials and feely available in Sri Lanka, the usage of them in bioethanol production is limited due to low ethanol yield and high processing cost [1][4]. From the perspective of the above-mentioned issues, any freely available proven waste material containing a considerable amount of fermentable sugar with low conversion cost, has gained wide attention.

Presently many researchers working on producing bioethanol aim towards vegetable and fruit wastes as a feasible substrate, which contains a high amount of fermentable sugar with limited processing steps [5][6].

Eng. (Mrs.) I.W. Kularathne, B.Sc. Eng. (Peradeniya), Lecturer in Mechanical Engineering, Faculty of Engineering University of Peradeniya, Sri Lanka.

Email:iwk@pdn.ac.lk

ORCID ID: https://orcid.org/0000-0002-8288-4430

Dr. C.A. Gunathilaka, B.Sc. Special (Hons) (Peradeniya), PhD (KSU, USA), Senior Lecturer in Chemical and Process Engineering, Faculty of Engineering, University of Peradeniya, Sri Lanka.

Email:chamilag@pdn.ac.lk

ORCID ID: https://orcid.org/0000-0001-7912-3940

Eng. (Dr.) A.C. Ratnaweera, B.Sc. Eng. (Hons) (Peradeniya), PhD (University of Melbourne), Senior Lecturer in Mechanical Engineering, Faculty of Engineering, University of Peradeniya, Sri Lanka.

Email:asangar@pdn.ac.lk

ORCID ID: https://orcid.org/0000-0002-8600-3418

Eng. (Dr). C.S. Kalpage, B.Sc. Eng. (Hons) (Moratuwa), PhD (University of Birmingham), Senior Lecturer in Chemical and Process Engineering, Faculty of Engineering,

University of Peradeniya, Sri Lanka.

Email:csk@pdn.ac.lk

ORCID ID: https://orcid.org/0000-0002-1937-2993

Prof. S. Rajapakse, B.Sc Special (Hons)(Peradeniya), PhD

(Hokkaido University, Japan), Faculty of Science, University

of Peradeniya, Sri Lanka.

Email:sanathr@pdn.ac.lk

ORCID ID: https://orcid.org/0000-0002-0014-5811

Eng. (Dr.) (Mrs.) P. Gamage, B.Sc. Eng. (Hons) (Peradeniya), PhD (Massey University, New Zealand), Senior Lecturer in Manufacturing and Industrial Engineering, Faculty of Engineering, University of Peradeniya, Sri Lanka.

Email:pramila.gamage@gmail.com

ORCID ID: https://orcid.org/0000-0003-4088-6144 
Overripe fruit mass (waste fruits) has been identified as an ideal substrate for bioethanol production with higher bioethanol yield [7], and Pseudomonas mendocina PM microorganism has been identified as an efficient microorganism to produce bioethanol through fermentation [8]. Sri Lanka being a tropical country, sugar-rich, mostly available fruits such as Banana, Papaya, Jackfruit, Watermelon, Star fruit, Sour soup, etc. are grown well in Sri Lanka. Out of those fruits, Banana, Papaya, and Jackfruit have been identified as the most sugar-rich fruits for the fermentation ethanol production [7]. It has been estimated that approximately 270000 tons of the harvested fruit in Sri Lanka is wasted annually due to improper post-harvesting activities [9] [10] [11]. Reference to Sarananda [9], about 20\% of Banana, $46 \%$ of Papaya, $18 \%$ of Pineapple, $40 \%$ of Lime, $41 \%$ of Avocado, and $90 \%$ of Jackfruit of the annual production in Sri Lanka are wasted [9].

Commonly, bioethanol is produced by the fermentation of the substrate using a bacterium. During the fermentation process, the growth of bacterial cells takes place, which involves various biochemical networks and chemical reactions [12][13]. By varying various fermentation factors such as agitation, aeration temperature, $\mathrm{pH}$, biomass concentration, type of microorganism, etc. the fermentation processes can be optimized [14] [15]. Thus, it is necessary to have a prior study on the optimization of the fermentation parameters to maximize the bioethanol yield. The conventional method of optimization is based on the change in one factor at one time while keeping the other factor constant. But the disadvantages of this method are a low degree of accuracy in the output, the necessity of a large number of experiments, waste of materials, and an increase in unreliability, etc. [16] [17].

Considering the drawbacks of the conventional optimization methods, some complex statistical oriented techniques such as Plackett-Burman, Central Composite Design, and Box-Behnken Design, etc. are available to predict, control, and optimize the bioprocess systems. Many researches have been reported on the optimization of ethanol production using response surface methodology with minimum numbers of tests. Using the test results, a surface plot is generated using advanced statistical software, which predicts the optimum values of each parameter referring to the generated surface [18][19]. In addition, some other advanced techniques, such as GA and PSO, are recently used for optimization. In GA and PSO, a regression equation is employed as a fitness function for the optimization of the function in accordance with the constraints provided [20][21].

Accordingly, the present study was carried out by fermentation of selected freely available Sri Lankan rotten fruits without skin in sample scale to maximize the ethanol yield using optimization tools. Fermentation was carried out by varying several fermentation parameters according to a design model: Box-Behnken Design for response surface optimization in order to select the best fermentation parameters for maximum ethanol yield [22]. GA and PSO based optimization techniques were carried out for the validation of the results.

\section{Materials and Methods}

\subsection{Selection of Fermentation Parameters}

Banana, Papaya, and Jackfruit were selected by using a prior experiment as the most sugar-rich three types of fruits for the fermentation process and ethanol production [7]. The best fermentation temperature for many fruits using Saccharomyces cerevisiae microorganism is $27^{\circ} \mathrm{C}$ to $30^{\circ} \mathrm{C}[23][24][25]$. In order to study the ethanol yield at higher temperatures, three different fermentation temperatures, 27, 32, and $35^{\circ} \mathrm{C}$, were selected. Reference to the literature, it was identified that the best $\mathrm{pH}$ values for the fermentation of fruits are in the range of 4.0 to 6.0 [23]. Accordingly, three different $\mathrm{pH}$ values $: 4.3,5.0$, and 5.7 were selected from that range. Three different concentrations of the fruit mass were selected as 1:1, 1:1.5 and 1:2 (w:w) of fruit to distilled water ratio [24][25[26].

\subsection{Raw Materials}

Banana (embul variety), Papaya, and Jackfruit were obtained from the local market. The best ripening stage of each fruit was determined by a prior experiment, and fruits were selected accordingly [7].

\section{$2.3 \quad$ Chemicals}

Yeast extracts, peptone and dextrose, were obtained from Techno Pharma Chem (Delhi, India). Glucose was obtained from the local market. Agar, Ammonium sulfate and Magnesium sulfate heptahydrate were obtained from Marine Chemicals (India). Potassium dihydrogen phosphate was obtained from Loba Chemie (Pvt) Ltd. (India). Potassium iodide and potassium dichromate were obtained from BDH Limited (England), concentrated 
sulphuric and sodium hydroxide were obtained from Dae-Jung Chemical \& Metal Co., Ltd Korea, and sodium thiosulfate was obtained from British Drug Houses Ltd. (London, UK).

\subsection{Use of Microorganism and Media}

Two types of microorganisms, baker's yeast and newly isolated naturally grown microorganism (PM) by a researcher of the Department of Molecular Biology and Biotechnology of University of Peradeniya (Gen Bank number of KU056820.1), were used for the fermentation. Pure cultures of baker's yeast were obtained by growing in standard Yeast Extract-Peptone-Dextrose (YPD) medium and pure cultures of PM were obtained by growing in standard glucose media [8].

\subsection{Sample Preparation}

Fruit juices with different solid contents were prepared by blending rotten fruit mass (without skin) with distilled water. Fruit pulps of different fruit to water ratios $(1: 1,1: 1.5$ and 1:2 (w:w)) were blended using a domestic blender (Panasonic mixer grinder, model number - MX-AC300). $100 \mathrm{ml}$ of each juice were poured into sterile $250 \mathrm{ml}$ conical flasks. $\mathrm{pH}(4.3,5,5.7)$ of each sample was adjusted using $0.1 \mathrm{NH}_{2} \mathrm{SO}_{4}$ and $0.1 \mathrm{~N} \mathrm{NaOH}$.

\subsection{Fermentation}

Bacterial suspension of $1 \mathrm{ml}$ (0.5 McFarland) was added into the fruit samples in $250 \mathrm{ml}$ conical flasks inside a laminar flow. The conical flasks were then air tightened with sterile cotton wool and aluminium foil to ensure the anaerobic condition, and incubated in a shaking incubator (AT 12 R) for the fermentation. Fermentation was carried out at three different $\mathrm{pH}$ values: $43,5.0$ and 5.7, three different temperatures: 29,32 , and $35^{\circ} \mathrm{C}$ at $85 \mathrm{rpm}$ for about 96 hours with yeast and 144 hours with PM microorganism. $5 \mathrm{ml}$ sample was taken out from each conical flask at 24hour intervals. The collected samples were centrifuged using a centrifuge (TOMY, Model No. suprema 21) for $20 \mathrm{~min}$ at $-4{ }^{\circ} \mathrm{C}$ at $10,000 \mathrm{rpm}$ to separate solid particles. The filtrate was collected to analyse the amount of reducing sugar and the concentration of ethanol. Duplicate samples were fermented, and ethanol and sugar concentration were measured.

\subsection{Sugar and Ethanol Concentration}

Sugar concentration of the filtrate was measured using a calibrated refract to meter (ATAGO, Model number -1T) while the concentration of ethanol of the filtrate was analysed using Gas Chromatography (SHIMADZU, Model No. C 114850). The average results of the ethanol concentration are tabulated in Table 3.

\subsection{Validation of Ethanol Concentration}

The ethanol concentration of few arbitrarily selected samples was then validated using dichromate reagent method and noted that the difference in readings between the two results was very small [27].

\subsection{Statistical Analysis}

Box-Behnken type Response Surface Method was used as the experimental method to optimize the ethanol yield obtained by fermentation of different fruits with each microorganism (Table 1). The three factors (temperature, $\mathrm{pH}$ and concentration of fruit) with two levels ( -1 for low level and +1 for high level) and each factor with one centre point (0center points) were selected as the most influential factors to see their effect on ethanol yield (Table 2) [22].

Table 1 - Layout of the Experiment

\begin{tabular}{|c|c|c|}
\hline $\begin{array}{c}\text { Experiment } \\
\text { No. }\end{array}$ & Fruit & Inoculum \\
\hline 1 & \multirow[b]{2}{*}{ Banana } & Saccharomyces cerevisiae \\
\hline 2 & & PM \\
\hline 3 & \multirow[b]{2}{*}{ Papaya } & Saccharomyces cerevisiae \\
\hline 4 & & PM \\
\hline 5 & \multirow[b]{2}{*}{ Jackfruit } & Saccharomyces cerevisiae \\
\hline 6 & & PM \\
\hline
\end{tabular}

Table 2 - Data Used for the Experimental Design

\begin{tabular}{|c|c|c|c|c|}
\hline Symbol & Test variable & \multicolumn{3}{|c|}{ Coded level } \\
\cline { 3 - 5 } & & -1 & 0 & 1 \\
\hline$X_{1}$ & Temperature & Room $\left(29{ }^{\circ} \mathrm{C}\right)$ & $32^{\circ} \mathrm{C}$ & $35^{\circ} \mathrm{C}$ \\
\hline $\mathrm{X}_{2}$ & $\mathrm{pH}$ & 4.3 & 5 & 5.7 \\
\hline $\mathrm{X}_{3}$ & Fruit to water concentration/(w:w) & $1: 1$ & $1: 1.5$ & $1: 2$ \\
\hline
\end{tabular}


Table 3 - Box-Behnken Design with Three Levels, the Observed and Predicted Ethanol Concentrations

\begin{tabular}{|c|c|c|c|c|c|c|c|c|c|c|c|c|}
\hline \multirow{4}{*}{$\begin{array}{l}\text { Run } \\
\text { order }\end{array}$} & \multicolumn{12}{|c|}{ Ethanol concentration /(vol\%) } \\
\hline & \multicolumn{4}{|c|}{ Banana } & \multicolumn{4}{|c|}{ Papaya } & \multicolumn{4}{|c|}{ Jackfruit } \\
\hline & \multicolumn{2}{|c|}{ Yeast } & \multicolumn{2}{|c|}{ PM } & \multicolumn{2}{|c|}{ Yeast } & \multicolumn{2}{|c|}{ PM } & \multicolumn{2}{|c|}{ Yeast } & \multicolumn{2}{|c|}{ PM } \\
\hline & Obs. & Pre. & Obs. & Pre. & Obs. & Pre. & Obs. & Pre. & Obs. & Pre. & Obs. & Pre. \\
\hline 1 & 10.3 & 10.1 & 12.6 & 13.0 & 4.0 & 3.9 & 4.4 & 4.3 & 5.6 & 5.3 & 6.9 & 7.0 \\
\hline 2 & 8.4 & 8.5 & 10.3 & 10.7 & 4.2 & 4.3 & 4.7 & 4.8 & 5.5 & 5.9 & 5.1 & 4.9 \\
\hline 3 & 7.5 & 7.4 & 10.9 & 10.3 & 4.4 & 4.2 & 4.4 & 4.5 & 5.8 & 5.8 & 5.8 & 5.8 \\
\hline 4 & 9.4 & 9.6 & 10.7 & 10.5 & 4.7 & 4.8 & 4.7 & 4.7 & 6.4 & 6.0 & 7.2 & 7.2 \\
\hline 5 & 7.1 & 7.0 & 10.3 & 10.1 & 4.9 & 4.8 & 5.4 & 5.0 & 5.8 & 5.6 & 5.9 & 6.1 \\
\hline 6 & 8.1 & 8.1 & 10.9 & 11.3 & 4.8 & 4.9 & 4.8 & 4.9 & 5 & 5.4 & 4.6 & 4.7 \\
\hline 7 & 9.6 & 9.5 & 12.3 & 12.4 & 3.8 & 3.9 & 4.5 & 4.8 & 5.9 & 5.7 & 6.8 & 7.1 \\
\hline 8 & 9.7 & 9.6 & 12.1 & 11.8 & 4.4 & 4.5 & 4.7 & 4.8 & 5.5 & 6.0 & 6.3 & 5.7 \\
\hline 9 & 9.2 & 9.2 & 11.7 & 12.0 & 4.6 & 4.5 & 5 & 4.9 & 6.6 & 6.5 & 7 & 6.9 \\
\hline 10 & 9.2 & 9.2 & 12.0 & 12.0 & 4.1 & 4.5 & 5 & 4.9 & 6.5 & 6.5 & 6.9 & 6.9 \\
\hline 11 & 7.3 & 7.4 & 10.8 & 10.3 & 4.1 & 4.2 & 4.4 & 4.5 & 6 & 5.8 & 5.8 & 5.8 \\
\hline 12 & 8.7 & 8.7 & 11.9 & 11.9 & 4.6 & 4.6 & 5 & 5.0 & 5.9 & 5.9 & 5.6 & 6.4 \\
\hline 13 & 9.5 & 9.0 & 12.3 & 11.2 & 4.1 & 4.7 & 4.4 & 5.0 & 5.8 & 6.3 & 6.9 & 7.2 \\
\hline 14 & 8.1 & 8.1 & 11.2 & 11.3 & 5.1 & 4.9 & 4.9 & 5.1 & 5.1 & 5.4 & 4.8 & 4.7 \\
\hline 15 & 9.2 & 9.2 & 12.0 & 12.0 & 4.5 & 4.5 & 5 & 4.9 & 6.3 & 6.5 & 6.9 & 6.9 \\
\hline 16 & 9.7 & 9.6 & 10.1 & 10.5 & 4.7 & 4.8 & 4.7 & 4.7 & 6.2 & 6.0 & 7.2 & 7.2 \\
\hline 17 & 8.5 & 8.5 & 13.3 & 13.2 & 3.5 & 3.6 & 4.8 & 4.4 & 5.4 & 5.6 & 6.5 & 6.5 \\
\hline 18 & 8.9 & 9.0 & 13.2 & 13.0 & 3.6 & 3.5 & 4.8 & 4.6 & 4.9 & 5.4 & 7.1 & 6.8 \\
\hline 19 & 9.6 & 9.6 & 11.9 & 12.0 & 3.9 & 4.0 & 4.6 & 4.5 & 5.6 & 5.9 & 6.6 & 6.5 \\
\hline 20 & 8.9 & 9.0 & 13.2 & 13.0 & 3.4 & 3.5 & 4.8 & 4.6 & 5.1 & 5.4 & 7.1 & 6.8 \\
\hline 21 & 8.5 & 8.5 & 10.3 & 10.7 & 4.3 & 4.3 & 4.6 & 4.8 & 5.6 & 5.9 & 5.2 & 4.9 \\
\hline 22 & 8.7 & 8.7 & 11.9 & 11.9 & 4.5 & 4.6 & 5.1 & 5.0 & 6.1 & 5.9 & 5.8 & 6.4 \\
\hline 23 & 9.9 & 10.1 & 12.7 & 13.0 & 3.7 & 3.9 & 4.5 & 4.3 & 5.3 & 5.3 & 7 & 7.0 \\
\hline 24 & 9.6 & 9.6 & 12.5 & 11.8 & 4.5 & 4.5 & 4.8 & 4.8 & 5.5 & 6.0 & 6.3 & 5.7 \\
\hline 25 & 8.6 & 8.5 & 13.5 & 13.2 & 3.6 & 3.6 & 4.7 & 4.9 & 5.3 & 5.6 & 6.5 & 6.5 \\
\hline 26 & 9.1 & 9.2 & 11.9 & 12.0 & 4.6 & 4.5 & 4.8 & 4.9 & 6.5 & 6.5 & 6.7 & 6.9 \\
\hline 27 & 9.2 & 9.2 & 12.1 & 12.0 & 4.7 & 4.5 & 5 & 4.9 & 6.3 & 6.5 & 7 & 6.9 \\
\hline 28 & 7 & 7.0 & 10.2 & 10.1 & 4.9 & 4.8 & 5.2 & 5.0 & 5.8 & 5.6 & 5.8 & 6.1 \\
\hline 29 & 9.1 & 9.2 & 11.8 & 13.1 & 4.5 & 3.7 & 4.8 & 4.7 & 6.5 & 5.8 & 6.7 & 7.1 \\
\hline 30 & 9.6 & 9.6 & 11.7 & 13.3 & 4.1 & 3.5 & 4.3 & 4.0 & 5.8 & 4.8 & 6.5 & 6.7 \\
\hline
\end{tabular}

In this experiment, the design matrix was setup using Box-Behnken three-factor design matrix with three centre runs and two replicates (30 experimental runs per one fruit type) with two types of microorganism, counting 180 experimental runs (Table 3) [28]. Table 3 shows the experimental ethanol concentrations, denoted as "Obs", with the predicted ethanol concentration denoted as "Pre". Predicted ethanol concentrations were obtained from the regression equations, obtained from statistical analysis.

Box-Behnken Response Surface Design was analysed using MINITAB17 software to fit models to the different sets of experimental data while identifying the significant factors and their optimum levels to find the maximum yield. In addition, regression analysis, analysis of variance (ANOVA), and response optimizer were also carried out to determine the optimized condition. Multiple box plots were taken from the same software to study the variability in the different data sets. Finally, 3-D surface plots were taken to study the effect of different factors on the ethanol concentration. Optimization was reconfirmed using GA analysis and PSO optimization tools by using the regression equations, obtained from RSM analysis as the fitness functions. GA optimization was carried out using MATLAB R2015a GA optimization tool, while PSO optimization was carried out with MATLAB R2015a software by programming with MATLAB. GA optimization was carried out by taking the lower bound as -1 and upper bound as +1 for all the factors and repeated several times with different initial conditions to see whether the optimization results vary with different initial conditions. After a different 
number of iterations ranging from 64 to 124 , with different fruit types, the global maximum of ethanol yield was obtained. PSO optimization was carried out with 500 iterations taking the lower and upper bound of the test variables as -1 and +1 for every three variables. ANOVA results for the Banana data are tabulated in Table 4 and obtained regression coefficients, P-values, and correlations $\left(\mathrm{R}^{2}\right)$ for the three types of fruit, with two different microorganisms are tabulated in Table 5 . Optimization results obtained by different optimization tools are tabulated in Table 6.

\section{Results and Discussion}

Optimization results obtained by three different optimization tools: RSM, GA, and PSO, are shown in Table 6. Reference to the results obtained from three different optimization tools, all the results seem similar, and the results of RSM and GA tools are exactly the same. Considering the overall optimization results in Table 6, the maximum predicted ethanol concentration of $13.39 \mathrm{vol} \%$ was determined by optimization with RMS from Banana (embul kesel variety) by fermentation with PM microorganism, under 1:1(w:w) substrate concentration, $\mathrm{pH} 5.1$ and $35^{\circ} \mathrm{C}$ temperature conditions. The optimization results using RMS have reconfirmed GA optimization results, however, it can be noted that optimum ethanol concentration has been reduced by optimization using PSO with a concentration of $13.36 \mathrm{vol} \%$ with the same fermentation conditions only with a small reduction of $\mathrm{pH}$ value to 5.07. Significant regression models at the 5\% level with high correlation values $\left(\mathrm{R}^{2}\right)$ were obtained as shown in Table 5. High correlation coefficient confirmed that the predicted ethanol concentration and the actual concentration in Table 3 are very close to each other. It further reveals that the experimental data could be accepted [28].

\subsection{Analysis of RSM Results}

\subsubsection{Analysis of Boxplot}

Figure 1 shows the boxplot of variation of the experimental ethanol concentrations of different fruits with different microorganisms. Reference to the Figure 1, the highest ethanol concentration has been achieved from Banana fruit by fermentation with PM microorganism. Second highest ethanol concentration could also be observed in Banana fruit fermentation with traditional yeast. Papaya and Jackfruit show very low ethanol concentration for the fermentation with both PM and traditional yeast. The results obtained for Papaya and Jackfruit can be comparable to the results discussed in the literature [24][25][26].

\subsubsection{ANOVA Results}

Table 4 shows the ANOVA analysis results for the Banana fruit by fermentation with PM microorganism and traditional yeast. Statistical analysis results show that three main factors (PH, Temperature, and fruit to water concentration) show a significant effect on ethanol concentration of Banana fruit fermentation with both microorganisms (Saccharomyces cerevisiae and PM) at a 5\% significant level. Furthermore, reference to the Table 5, ANOVA results show that two-way interactions $\left(X_{1} X_{2}\right.$ and $\left.X_{2} X_{3}\right)$ and a square term

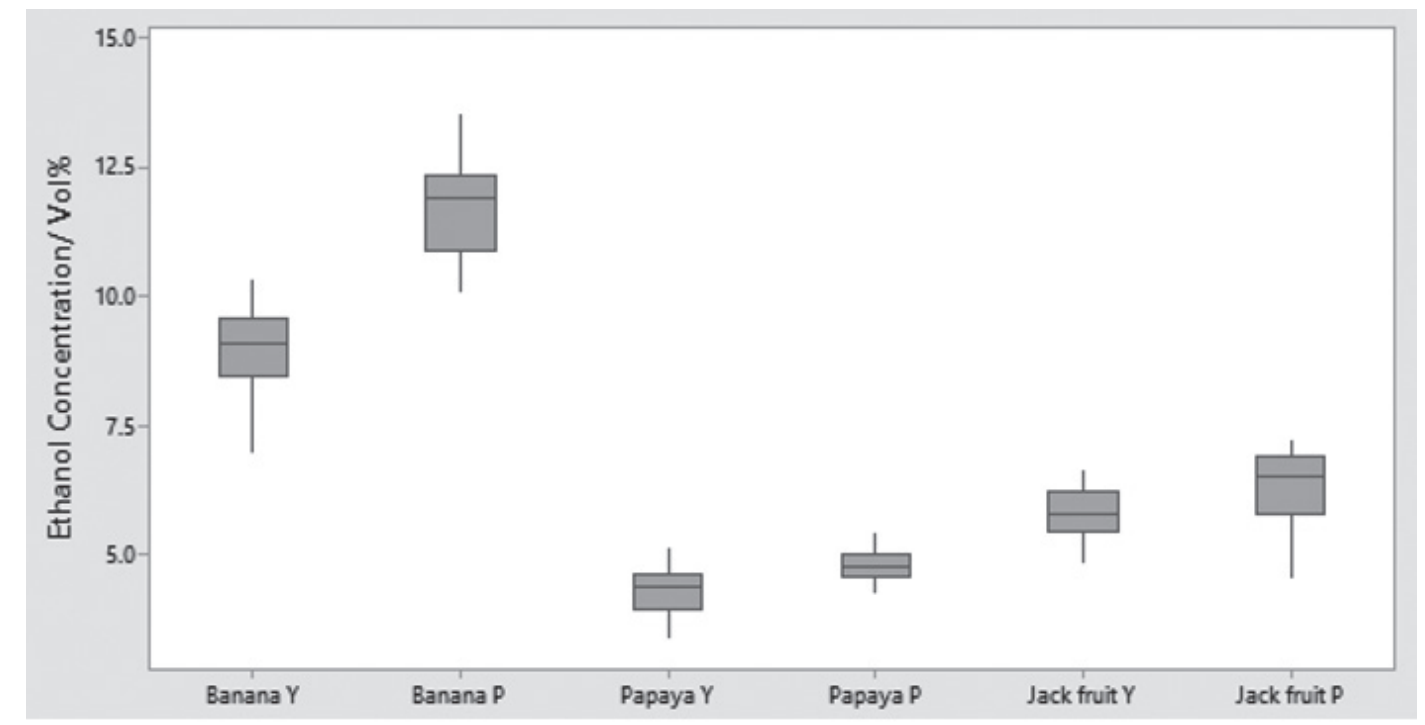

Figure 1 - Boxplot of Variation of Ethanol Concentration with Different Fruits and Microorganisms 
Table 4 - ANOVA for the Quadratic Polynomial Model on the Ethanol Production - Banana

\begin{tabular}{|l|c|c|c|c|c|c|c|c|c|c|}
\hline \multicolumn{1}{|c|}{ Source } & \multicolumn{3}{|c|}{$\begin{array}{l}\text { Degrees of } \\
\text { freedom (DF) }\end{array}$} & \multicolumn{3}{|c|}{ Sum of squares } & \multicolumn{2}{c|}{$\begin{array}{c}\text { Fean square } \\
\text { (MS) }\end{array}$} & \multicolumn{3}{c|}{ P-value } \\
\hline & Yeast & PM & Yeast & PM & Yeast & PM & Yeast & PM & Yeast & PM \\
\hline Regression & 9 & 6 & 20.4091 & 26.8212 & 2.26768 & 4.4707 & 216.40 & 79.55 & 0.000 & 0.000 \\
\hline Linear & 3 & 3 & 10.7488 & 23.3100 & 3.58292 & 7.7700 & 341.91 & 138.27 & 0.000 & 0.000 \\
\hline Square & 3 & 1 & 4.6228 & 1.2590 & 1.54094 & 1.2590 & 147.05 & 22.40 & 0.000 & 0.000 \\
\hline Interaction & 3 & 2 & 5.0375 & 1.6029 & 1.67917 & 0.8015 & 160.24 & 14.26 & 0.000 & 0.000 \\
\hline Residual error & 20 & 23 & 0.2096 & 1.2924 & 0.01048 & 0.0562 & - & - & - & - \\
\hline Lack of fit & 3 & 6 & 0.0262 & 0.5774 & 0.00875 & 0.0962 & 0.81 & 2.29 & 0.505 & 0.084 \\
\hline Pure error & 17 & 17 & 0.1833 & 0.7150 & 0.01078 & $0 . .0421$ & & & & \\
\hline Total & 29 & 29 & 20.6118 & 28.1137 & & & & & & \\
\hline
\end{tabular}

Table 5 - Regression Coefficients and P Values

\begin{tabular}{|c|c|c|c|c|c|c|c|c|c|c|c|c|}
\hline \multirow{3}{*}{$\begin{array}{c}\text { Model } \\
\text { term }\end{array}$} & \multicolumn{4}{|c|}{ Banana } & \multicolumn{4}{|c|}{ Papaya } & \multicolumn{4}{|c|}{ Jackfruit } \\
\hline & \multicolumn{2}{|c|}{ Yeast } & \multicolumn{2}{|c|}{ PM } & \multicolumn{2}{|c|}{ Yeast } & \multicolumn{2}{|c|}{ PM } & \multicolumn{2}{|c|}{ Yeast } & \multicolumn{2}{|c|}{ PM } \\
\hline & $\begin{array}{l}\text { Regre. } \\
\text { Coef. }\end{array}$ & $\begin{array}{c}\mathrm{P}- \\
\text { value }\end{array}$ & $\begin{array}{l}\text { Regre. } \\
\text { Coef. }\end{array}$ & $\begin{array}{c}\mathrm{P}- \\
\text { value }\end{array}$ & $\begin{array}{l}\text { Regre. } \\
\text { Coef. }\end{array}$ & $\begin{array}{c}\mathrm{P}- \\
\text { value }\end{array}$ & $\begin{array}{l}\text { Regre. } \\
\text { Coef. }\end{array}$ & $\begin{array}{c}\mathrm{P}- \\
\text { value }\end{array}$ & $\begin{array}{l}\text { Regre. } \\
\text { Coef. }\end{array}$ & $\begin{array}{c}\mathrm{P}- \\
\text { value }\end{array}$ & $\begin{array}{l}\text { Regre. } \\
\text { Coef. }\end{array}$ & $\begin{array}{c}\mathrm{P}- \\
\text { value }\end{array}$ \\
\hline $\mathrm{X}_{1}$ & 0.7625 & 0.000 & 1.1375 & 0.000 & -0.4362 & 0.000 & -0.0938 & 0.003 & -0.0812 & 0.016 & 0.7375 & 0.000 \\
\hline $\mathrm{X}_{2}$ & 0.2188 & 0.000 & 0.3291 & 0.000 & -0.2363 & 0.000 & -0.1063 & 0.001 & -0.2750 & 0.000 & -0.0625 & 0.024 \\
\hline $\mathrm{X}_{3}$ & 0.2063 & 0.000 & -0.2901 & 0.000 & -0.0875 & 0.030 & -0.1750 & 0.000 & 0.1813 & 0.000 & 0.4125 & 0.000 \\
\hline $\mathrm{X}_{1} \mathrm{X}_{1}$ & -0.7583 & 0.000 & - & - & -0.3084 & 0.000 & -0.1288 & 0.005 & -0.6688 & 0.000 & -0.5396 & 0.000 \\
\hline $\mathrm{X}_{2} \mathrm{X}_{2}$ & 0.0792 & 0.048 & -0.4155 & 0.000 & - & - & - & - & -0.2312 & 0.000 & -0.0896 & 0.027 \\
\hline $\mathrm{X}_{3} \mathrm{X}_{3}$ & 0.1292 & 0.003 & - & - & - & - & -0.1913 & 0.000 & -0.3437 & 0.000 & -0.3396 & 0.000 \\
\hline $\mathrm{X}_{1} \mathrm{X}_{2}$ & -0.5125 & 0.000 & 0.2125 & 0.018 & - & - & 0.2500 & 0.000 & -0.1500 & 0.003 & 0.2375 & 0.003 \\
\hline $\mathrm{X}_{1} \mathrm{X}_{3}$ & 0.5625 & 0.000 & - & - & 0.2500 & 0.000 & - & - & - & - & -0.1625 & 0.000 \\
\hline $\mathrm{X}_{2} \mathrm{X}_{3}$ & -0.2250 & 0.000 & 0.4073 & 0.000 & 0.1500 & 0.010 & - & - & -0.1875 & 0.000 & -0.3125 & 0.000 \\
\hline $\mathrm{R}^{2}$ & \multicolumn{2}{|c|}{$98.98 \%$} & \multicolumn{2}{|c|}{$95.40 \%$} & \multicolumn{2}{|c|}{$91.23 \%$} & \multicolumn{2}{|c|}{$85.31 \%$} & \multicolumn{2}{|c|}{$95.17 \%$} & \multicolumn{2}{|c|}{$98.69 \%$} \\
\hline Adj $R^{2}$ & \multicolumn{2}{|c|}{$98.53 \%$} & \multicolumn{2}{|c|}{$94.20 \%$} & \multicolumn{2}{|c|}{$88.94 \%$} & \multicolumn{2}{|c|}{$81.48 \%$} & \multicolumn{2}{|c|}{$93.33 \%$} & \multicolumn{2}{|c|}{$98.11 \%$} \\
\hline Pre $\mathrm{R}^{2}$ & \multicolumn{2}{|c|}{$97.47 \%$} & \multicolumn{2}{|c|}{$91.28 \%$} & \multicolumn{2}{|c|}{$96.10 \%$} & \multicolumn{2}{|c|}{$73.61 \%$} & \multicolumn{2}{|c|}{$89.92 \%$} & \multicolumn{2}{|c|}{$97.31 \%$} \\
\hline
\end{tabular}

Table 6 - Optimization Results

\begin{tabular}{|c|c|c|c|c|c|c|}
\hline Fruit & Inoculum & $\begin{array}{c}\text { Optimization } \\
\text { tool }\end{array}$ & $\begin{array}{c}\text { Temperature } \\
\text { / }{ }^{\circ} \mathrm{C} \\
\end{array}$ & $\mathrm{pH}$ & $\begin{array}{c}\text { Concentration } \\
\qquad /(\mathrm{w}: \mathrm{w})\end{array}$ & $\begin{array}{l}\text { Predicted max. vol\% } \\
\text { ethanol concentration }\end{array}$ \\
\hline \multirow{6}{*}{ Banana } & \multirow{3}{*}{$\begin{array}{c}\text { Saccharomyces } \\
\text { cerevisiae }\end{array}$} & RSM & 35.0 & 4.3 & $1: 2$ & 10.67 \\
\hline & & GA & 35.0 & 4.3 & $1: 2$ & 10.67 \\
\hline & & PSO & 35.0 & 4.3 & $1: 2$ & 10.67 \\
\hline & \multirow{3}{*}{ PM } & RSM & 35.0 & 5.10 & $1: 1$ & 13.39 \\
\hline & & GA & 35.0 & 5.11 & $1: 1$ & 13.39 \\
\hline & & $\mathrm{PSO}$ & 35.0 & 5.07 & $1: 1$ & 13.36 \\
\hline \multirow{6}{*}{ Papaya } & \multirow{3}{*}{$\begin{array}{c}\text { Saccharomyces } \\
\text { cerevisiae }\end{array}$} & RSM & Room (29) & 4.3 & $1: 1$ & 5.01 \\
\hline & & GA & Room (29) & 4.3 & $1: 1$ & 5.01 \\
\hline & & $\mathrm{PSO}$ & Room (29) & 4.3 & $1: 1$ & 5.01 \\
\hline & \multirow{3}{*}{ PM } & RSM & Room (29) & 4.3 & $1: 1.3$ & 5.29 \\
\hline & & GA & Room (29) & 4.3 & $1: 1.3$ & 5.29 \\
\hline & & $\mathrm{PSO}$ & Room (29) & 4.3 & $1: 1.4$ & 5.25 \\
\hline \multirow{6}{*}{ Jackfruit } & \multirow{3}{*}{$\begin{array}{c}\text { Saccharomyces } \\
\text { cerevisiae }\end{array}$} & RSM & 31.9 & 4.6 & $1: 1.6$ & 6.56 \\
\hline & & GA & 31.9 & 4.6 & $1: 1.6$ & 6.56 \\
\hline & & PSO & 31.0 & 4.6 & $1: 2$ & 6.33 \\
\hline & \multirow{3}{*}{ PM } & $\mathrm{RSM}$ & 32.9 & 4.3 & $1: 2$ & 7.27 \\
\hline & & GA & 32.9 & 4.3 & $1: 2$ & 7.27 \\
\hline & & PSO & 32.8 & 4.3 & $1: 2$ & 7.23 \\
\hline
\end{tabular}


$\left(X_{2} X_{2}\right)$ have a significant effect on the ethanol concentration of Banana fruit by fermentation with PM microorganism at a $5 \%$ significance level. There is a significant effect from all threesquare terms $\left(X_{1} X_{1}, X_{2} X_{2}\right.$, and $\left.X_{3} X_{3}\right)$ and three two-way interactions $\left(X_{1} X_{2}, X_{1} X_{3}\right.$, and $\left.X_{2} X_{3}\right)$ on ethanol concentration of Banana fruit fermentation with traditional yeast at 5\% significance level.

\subsubsection{Regression Equations}

Regression coefficients and the $\mathrm{p}$ values obtained from ANOVA analysis for the fermentation of three fruit types with both microorganisms, PM and traditional yeast (six sets of experimental data), are tabulated in Table 5. Reference to Table 5, it could be noticed that all three main factors $\left(X_{1}, X_{2}\right.$ and $\left.X_{3}\right)$ have a significant effect on ethanol concentration of three types of fruit fermentation, with both microorganisms at 5\% significance level. The square term $X_{1} X_{1}$ shows a significant effect on all three fruits except Banana fermentation with PM. The square term $X_{2} X_{2}$ has a significant effect on Banana and Jackfruit fermentation with both microorganisms. The $X_{3} X_{3}$ square term also shows a significant effect on all fruits except Banana fermentation with PM and Papaya fermentation with yeast. The two-way interaction term, $\mathrm{X}_{1} \mathrm{X}_{2}$ shows a significant effect on all three types of fruits except Papaya fermentation with yeast. The $X_{1} X_{3}$ two-way interaction has a significant effect on Banana and Papaya fermentation with yeast, and Jackfruit fermentation with PM. The $\mathrm{X}_{2} \mathrm{X}_{3}$ twoway interaction has a significant effect on all three types of fruit except Papaya fermentation with PM. Furthermore, the final regression models explain the majority of the variation at a satisfactory level with $\mathrm{R}^{2}>85.31 \%$. Model adequacy was tested for all the models by checking residual plots, four in one plot, etc. which have been produced from MINITAB 17 statistical software. It was noted that all the models fulfilled the assumptions: homoscedasticity, normally distributed residuals, and independence of residuals (no autocorrelation), and therefore it implies the "model adequacy" [28].

Predicted ethanol concentration in Table 3 was obtained by substituting the relevant coded levels to the six equations. Reference to Table 3, it clearly shows that the highest ethanol concentration can be obtained using Banana fermentation with PM. Second highest ethanol concentration can be obtained using Banana with traditional yeast. The negligible difference in the predicted and the observed ethanol concentration could be expected due to experimental errors.

Out of the obtained six regression equations from regression analysis, the regression equation of the selected fruit: Banana by fermentation with PM microorganism is given in equation 1.

$\left.\mathrm{Y}_{(\text {Banana, }} \mathrm{PM}\right)=11.9571+1.1375 \mathrm{X}_{1}+0.3291 \mathrm{X}_{2}-0.2901 \mathrm{X}_{3}-$

$0.4155 \mathrm{X}_{2}{ }^{*} \mathrm{X}_{2}+0.2125 \mathrm{X}_{1}{ }^{*} \mathrm{X}_{2}+0.4073 \mathrm{X}_{2}{ }^{*} \mathrm{X}_{3}+\varepsilon$

where $\varepsilon$ is the random error.

3.1.4 Three-dimensional surface plots for the ethanol yield of Banana fruit by fermentation with PM

Three-dimensional surface plots were generated for the pair-wise combination for ethanol production using Banana fruit with PM microorganism for each test variable: temperature, $\mathrm{pH}$, and biomass concentration, as shown in Figure 2, Figure 3, and Figure 4. pH range (the hydrogen ion concentration in the fruit pulp) is an important factor affecting cell growth and metabolite production and thereby the rate of fermentation [29]. Figure 2 shows that ethanol concentration significantly increases with increasing temperature.

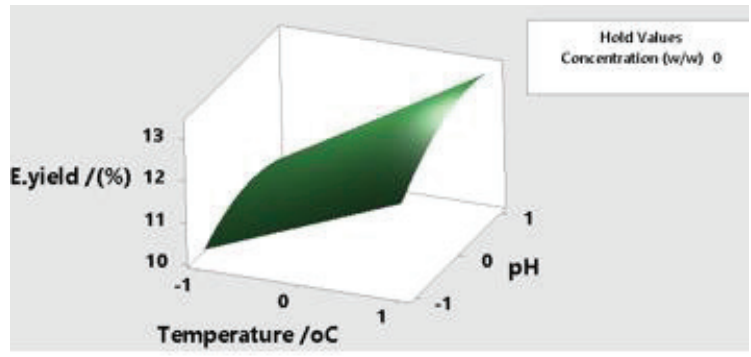

Figure 2 - Surface Plot for the Effect of Type of Temperature and $\mathrm{pH}$ on the Ethanol Concentration

The highest ethanol yield was observed at $35^{\circ} \mathrm{C}$ temperature, and $\mathrm{pH} \sim 5$. Further, it could be noted that both $\mathrm{pH}$ and temperature are crucial factors for the fermentation of fruits for ethanol production [30]. Reference to the surface plot in Figure 3, the highest ethanol yield could be obtained at $\mathrm{pH} \sim 5$, and fruit to water concentration of 1:1 (w:w).

Reference to Figure 4, ethanol yield is increasing linearly with increasing fermentation temperature. The highest ethanol concentration could be obtained at $35^{\circ} \mathrm{C}$ temperature and 1:1 
(w:w) fruit to water concentration. Finally, the highest ethanol concentration could be obtained by fermentation Banana fruit using PM when the temperature is set at $35^{\circ} \mathrm{C}, \mathrm{pH}$ value is set at 5 , and fruit to water concentration is set at 1:1 (w:w).

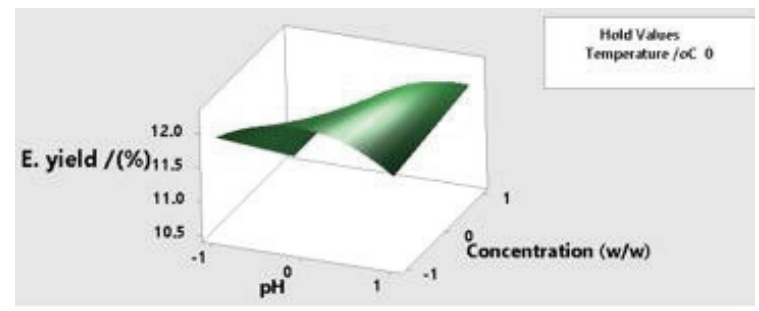

Figure 3 - Surface Plot for the Effect of $\mathrm{pH}$ and Biomass Concentration on the Ethanol Concentration

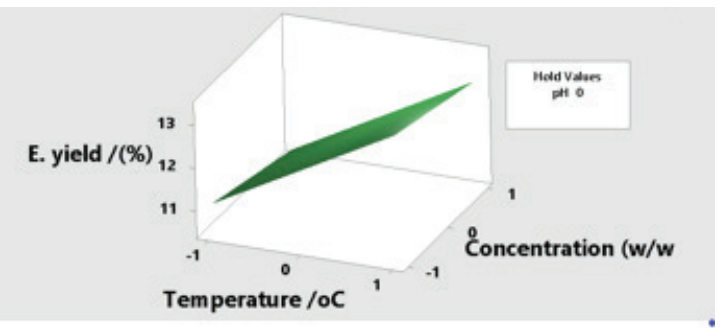

Figure 4 - Surface Plot for the Effect of Temperature and Biomass Concentration on the Ethanol Concentration

\subsection{Optimization with Genetic}

Algorithm (GA)

GA optimization results obtained with different initial conditions were compared to see whether the initial parameters have an effect on the optimization results and noted that the maximum ethanol concentration is the same with different initial conditions for all the fruit types with two different microorganisms, studied. By comparing the overall optimization results in Table 6 , it could be noted that the optimization results obtained from GA and RSM are almost the same.

\section{References}

1. O'scar, J. \& Carlos. A., "Trends in Biotechnological Production of Fuel Ethanol from different Feedstocks - A Review", Journal of Bioresource Technology, vol. 99, 2008, pp. 52705295.

2. Isitua, C., \& Ibeh, I., "Novel Method of Wine Production from Banana (Musa acuminata) and Pineapple (Ananascomosus) wastes", African Journal of Biotechnology, vol. 09, 2010, pp. 75217524.

\subsection{Particle Swarm Optimization}

For PSO, optimization was carried out with 500 iterations to obtain global maximum values for the maximum ethanol concentrations. Reference to Table 6, the optimum ethanol concentrations obtained from PSO optimization are quite close to the results obtained from RSM and GA.

\section{Conclusion}

This study investigated ethanol production using three different, freely available, Sri Lankan fruits by fermentation with two different micro-organisms under different fermentation conditions to optimize the ethanol yield. Considering the experimental results, the following conclusions could be made.

1. Overripe Banana (embul kesel variety) fruit mass could be used for ethanol production by fermentation with PM, a novel microorganism.

2. A maximum ethanol concentration of $13.39 \%(\mathrm{v} / \mathrm{v})$ could be obtained by fermentation of Banana (embul kesel variety) fruit mass with PM microorganism at $35^{\circ} \mathrm{C}, \mathrm{pH}=5$ with fruit to water concentration of $1: 1(w: w)$.

3. Relatively same optimization results were obtained by optimization of the ethanol production process using RSM GA and PSO.

4. Commercial-scale ethanol production could be recommended from Banana (embul kesel variety) by fermentation using PM microorganism.

\section{Acknowledgment}

Financial assistance by the University Grant Commission (UGC) is highly appreciated (Grant No. UGC/VC/DRIC/PG2015(III)/PDN/01).

3. Hägerdal, H., Galbe, B., Grauslund, G., Liden, M., \& Zacch, G., "Bio-ethanol--the Fuel of Tomorrow from the Residue of Today", Trends Bio-technol, vol. 24, No. 12, 2006, pp. 549-556.

4. Claassen, P., Van, L., López, C., Van, N., Sijtsma, L., Stams, A., de Vries, S., \& Weusthuis, R., "Utilization of Biomass for the Supply of Energy Carriers", Microbiology and Biotechnology, vol. 21, No. 03, 1999, pp. 207-211. 
5. Avinash, K., "Biofuels (Alcohols and Biodiesel) Applications as Fuels for Internal Combustion Engines", Progress in Energy and Combustion Science, vol. 33, No. 03, 2007, pp. 233-271.

6. Perera, S., Ratnasinghe, R. M. C. G., Mahawatta, D. C. G., Perera, M. A. S., Perera, D., Mahesh, K. W. C., \& Walliwala, S. G., "Manufacture of bioethanol from Vegetable and Fruit Waste in Sri Lanka", in 24th International Conference on Solid Waste Technology and Management, PA USA, March 15-18, 2009.

7. Kularathne, I., Rajapakse, S., Kalpage, C., \& Rathnaweera, A., "Comparision of Sugar Contents of Six Selected Sri Lankan Fruits", Proceedings of PGIS Research Congress, Peradeniya, 7-8 October, 2016.

8. Rukshika, S., Sisira, K., Sanath, R.,\& Subramanium, S., "Isolation and Characterization of an Ethanol Resistant Bacterium from Sap of Saccharum officinarum for Efficient Fermentation", International Journal of Biotechnology and Bioengineering, vol. 03, No. 02, 2016, pp. 15-20.

9. Sarananda, K., "Appropriate Postharvest Technologies for Horticultural Crops in Sri Lanka. Inappropriate Postharvest Technologies for Horticultural Crops in Asia", Asian productivity Organization, Tokyo, 2000.

10. Wasala, W. M. C. B., Gunawardhane, R., Champa, W. A. H., Wijewardhane, R. M. N. A. , Rathnayake, R. M. R. N. K., Chandrajith, U. G., \& Thilakarathne, B. M. K. S., "Assessment of Postharvest Losses and Quality Deteriorations of BananaFruits During Supply Chain Activities in Sri Lanka", 2014.

11. Kodippili, I. I. H., "Minimise Postharvest Losses ofFruits to Ensure Food Security",Daily News, 10 th November, 2016.

12. Jurtshuk, P., \& Baron, S., "Bacterial Metabolism", Medical Microbiology, $4^{\text {th }}$ ed., Galveston University of Texas, Medical Branch, 1996, p.56.

13. Joachim, A., Marija, C., Vassily, H., \& Jens, N., "Kinetic Models in Industrial Biotechnology Improving Cell Factory Performance", Metabolic Engineering, vol. 24, 2014, pp. 38-60.

14. Hossain, Z., Golam, F., Jaya, N., Mohd, S., Rosli, H.,\& Amru, N., "Bioethanol Production from Fermentable Sugar Juice", Scientific World Journal, 2014, pp. 1-12.
15. Nikolic, S., Mojovic, L., Rakin, M.,\& Pejin, D., "Bioethanol Production from Cornmeal by Simultaneous Enzymatic Saccharification and Fermentation with Immobilized Cells of Saccharomyces Cerevisiae var. Ellipsoids",Fuel, vol. 88, 2009,pp. 1602-1607.

16. Vineeta, S., Shafiul, H., Ram, N., Akansha, S. Mukesh, P., \& Tripathi, C., "Strategies for Fermentation Medium Optimization: An InDepth Review", Front Microbiology, vol. 07, 2016, pp. 2077-2085.

17. Nanthaporn, T., \& Niorn, C., "Fermentation of Pineapple Juice using Wine Yeast: Kinetics and Characteristics", Asian Journal of Food and AgroIndustry, vol. 01, No. 01, 2013, pp. 1-10.

18. Karuppaiya, M., Sasikumar, E., Viruthagiri, T.,\& Vijayagopal, V., "Optimization of Process Conditions using Response Surface Methodology (RSM) for Ethanol Production from Waste Cashew Apple Juice by Zymomonasmobilis", Chemical Engineering Communications, vol. 196, 2009, pp. 1425-1435.

19. Rosma, A., Liong, M., Mohd, A., \& Wan, N., "Optimization of Single Cell Protein Production by Candida Utilize using Juice extracted from Pineapple waste through Response Surface Methodology", Malaysian Journal of Microbiology, vol. 1, 2005, pp. 18-24.

20. Maiti, B., Rathore, A., Srivastava, S., Shekhawat, M., \& Srivastava, P., "Optimization of Process Parameters for Ethanol Production from Sugar Cane Molasses by Zymomonas Mobilis using Response Surface Methodology and Genetic Algorithm", Applied Microbiology and Biotechnology, vol. 90, No. 1, 2001, pp. 385-395.

21. Yudong, Z., Shuihua, W.,\& Genlin, J., "A Comprehensive Survey on Particle Swarm Optimization Algorithm and Its Applications", Mathematical Problems in Engineering, vol. 3, 2015, pp. 38-45.

22. Nadya, H. Zainal, S., Atikah, O., \& Tengk, E. T., "Optimization of Ethanol Fermentation from Pineapple Peel Extract Using Response Surface Methodology (RSM)", International Journal of Nutrition and Food Engineering, vol. 6, No. 12, 2012, pp. 1102-1108.

23. Lee, J., Biochemical Engineering. 1st ed., Albright's Chemical Engineering Handbook, Florida: Taylor \& Francis Group, LLC, 2008, pp. 1529-1537.

24. Hammond, J., Richard, E., Drew, D., \& Charlie, G., "Alcohol from Bananas", BioResource Technology, vol. 56, 1996, pp. 125-130. 
25. Akin-Osaniye, B., Nzelibe, H., \& Agbaji, A., "Ethanol Production from Carica Papaya (Pawpaw) Fruit Waste", Asian Journal of Biochemistry, vol. 03, No. 03, 2008, pp. 188-193.

26. Nirmal, S., Sonam, P., \& Danesh, A., "Process Optimization for Fermentation of Wine from Jackfruit", Journal of Food Processing and Technology, vol.0 4, No. 02, 2012, pp. 1-5.

27. William, M. B., \& Reese, D., "Colorimetric Determination of Ethyl Alcohol", Analytical Chemistry, vol. 22, No.12, 1950, pp. 1556-1561.

28. Montgomery, D. C., Design and Analysis of Experiments, Hoboken: NJ, John Wiley \& Sons, 2013.
29. Buzás, Z., Dallmann, K. \& Szajani, B., "Influence of $\mathrm{pH}$ on the Growth and Ethanol Production of Free and Immobilized Saccharomyces Cerevisiae Cells", Botechnology and bioengineering, vol. 34, No. 6, 1989, pp. 882-886.

30. Sankh, S. N., Deshpande, P. S., \& Arvindekar, A. U., "Improvement of Ethanol Production using Saccharomyces Cerevisiae by Enhancement of Biomass and Nutrient Supplementation", Applied Biochemistry and Biotechnology, vol. 164, No. 08, 2011, pp. 1237-1245. 